\title{
The Present Situation and The Path Analysis of Leisure Agriculture Resources Development
}

\author{
Bao Wu-lan-tuo-ya \\ Cooperatives college, Qingdao Agricultural University, Qingdao 266109, China \\ wlty928@163.com
}

Keywords:Leisure Agriculture; Leisure Agricultural Resources; Leisure Farm

\begin{abstract}
Leisure agriculture is the embodiment and extension of agricultural production, rural life and agricultural ecological functions.The recreational value and development potential of distinctive leisure agriculture resources appear more and more important. Leisure agriculture resource exploitation scale grow year by year,develop type tend to diversify, the spatial distribution present cluster development trend. Through analysis the recreation opportunities and development characteristics of leisure agricultural resources, the thesis explore leisure agriculture resource development path, focuses on the development of leisure agriculture park type such as sightseeing type, science and technology type , and education-based type, procreative type and industrial type leisure farms, as well as folk village.Spatial layout mainly for the scenic edge type, urban suburban type, specialty farming area type.Resource development organizational model can be described as government-led, business-led and self-employed three forms.

In recent years, the rapid development of the Chinese tourism industry, leisure agriculture has become the focus of the tourism development, economic and social progress, industrial structure adjustment, social consumption ability also offers the opportunity for the leisure agriculture resources development.
\end{abstract}

\section{Leisure agriculture resources characteristics and classification}

The connotation of leisure agricultural resources.Leisure resource is able to appeal to people and meet their leisure needs,such as agricultural production, rural folk customs, agricultural ecological environment etc. These agricultural objects are composed of attracting natural and social elements.

Leisure agriculture resources features are different from the traditional tourism resources:productbility and amusement. Leisure agriculture resources can be used for agricultural production and processing, and also for recreation. Seasonal. The growth and development of crops is closely linked with seasonal change of light,temperature,rainfall,and shows periodic characteristic. Regionalism. Include geographical differences caused by natural environment factors and the formation of different cultures based on differences in the social environment.Ecological. Leisure agriculture resources take the ecological system as the foundation, the growth of plants and animals, habitat, reproduction, people's production and social life have a close relationship with the ecological environment. Sustainability. Renewability of leisure agriculture natural resources and inheritability of agricultural social resources led to the sustainable features of development and utilization.

Leisure agriculture resources classification.Leisure agriculture resources are various, they are closely related with the agriculture industry characteristics, farmers living culture, ecological landscape of leisure tourism destination. According to the combining characteristics of leisure agric ulture production, agriculture life and agriculture ecology, which is known as three property integration,the leisure agriculture resources fall into three categories:leisure agricultural production resources,leisure agriculture life resources and leisure agriculture ecological resources. Leisure agricultural production resources divided into agricultural cultivation resources, farming activities resources, farm tools resources, agricultural breed resources; leisure agricultural life resources composed of farmers' special resources, daily life resources, traditional architectural resources, cultural celebrations resources.Leisure agricultural ecological resources include rural meteorological resources, rural geography resources, rural biological resources, rural e nergy resources and rural landscape resources. 


\section{Leisure agriculture resources development present situation}

Along with speeding up of urbanization, urban and rural residents' disposable income and consumption expenditure ability enhancement, residents' consumption mode and the change of consumption structure, leisure agriculture entered rapid development stage from preliminary development stage.

Leisure agricultural resources development scale.At present,chinese leisure agricultural resources development has changed from the spontaneous small scale stage to the professional operation stage. Chinese leisure agriculture and rural tourism research results show that: up to 2012, the village developed leisure agriculture and rural tourism activity achieve 85000,leisure agriculture and rural tourism operation entity already amounted to 1.7 million, whereas agricola accounted for 88\%, amounted to 1.5 million; employees amounted to 28 million,accounted for $6.9 \%$ in total rural labor force ; receive a total of 8 billion tourists in 2013, the annual revenue reach 2400 billion yuan. The investigation of agriculture township enterprises ministry based on 135000 leisure agriculture management entity shows that: farmhouse,leisure farms, agricultural park,folk village and other forms of business entity have been drive 1.968 million surrounding farmer become rich. An important source of leisure agriculture income is agricultural byproduct sales revenue, accounting for $54.6 \%$ of the total business income.Chinese leisure agricultural resources development have relatively high rate of return on investment,leisure agriculture investment output rate up to 61\%, profit rate reached 19\%;the average output value of the agricultural land up to 29000 yuan of per hectare, whereas leisure agriculture land average output value reached 180000 yuan of per hectare, the profit amounted to 55000 yuan of per hectare, land input-output rate is high; leisure agricultural workers per capita labor output value reach 54000 yuan, the per capita labor profit reach 16000 yuan,it is 2.75 times than the national agricultural labor force per capita output in same period.

Leisure agriculture resources development type.In order to speed up the development of leisure agriculture, transform agricultural development mode, expand agricultural function and meet the leisure demand of resident consumer, The Ministry of Agriculture and the National Tourism Administration from 2004 to carry out the national leisure agriculture demonstration site establish activities. By the end of 2013, 742 leisure agriculture demonstration site already established, choosing leisure agriculture unit which have strong demonstration effect, management specification, perfect service function, complete infrastructure,high quality practitioners to strengthen promotion. At present,,among 742 leisure agriculture demonstration sites,the agricola is23,accounting for 3.1\%. there are 413 leisure agricultural parks,among them:242 agricultural sightseeing parks,accounting for 32.61\%;120 agricultural ecological parks,accounting for $16.17 \% ; 51$ agricultural base parks,accounting for 6.87\%;95 leisure farms,accounting for 12.8\%; 108 special townships ,accounted for $14.5 \%$.

Leisure agriculture resources development layout.Leisure agriculture demonstration sites overall distribution characteristics.Leisure agriculture demonstration sites showed uneven distribution in each region.Judging from the demonstration sites number, Beijing, Tianjin, Hebei,Shanghai, Jiangsu,Zhejiang, Fujian, Shandong,Guangdong, Hainan 10 eastern provinces have 301 ,accounting for $40.57 \%$,among them,Shandong,Jiangsu,Liaoning provinces reached $24.4 \%$ of the total;Shanxi,Anhui,Jiangxi,Henan,Hubei,Hunan 6 central provinces have 127,accounting for $17.12 \%$ of the total;Inner Mongolia, Guangxi, Sichuan,Chongqing, Guizhou, Yunnan, Tibet, Shanxi, Gansu,Qinghai, Ningxia, Xinjiang 12 west provinces have 231,accounting for 31.13\% of the total; Liaoning, Jilin, Heilongjiang northeast provinces have 83 , accounting for $11.19 \%$ of the total.

Table 1 Leisure agriculture demonstration sites provincial distribution

\begin{tabular}{cccccc}
\hline Province & $\begin{array}{c}\text { Demonstr } \\
\text { ation sites }\end{array}$ & $\begin{array}{c}\text { Percentage } \\
{[\%]}\end{array}$ & Province & $\begin{array}{c}\text { Demonstr } \\
\text { ation sites }\end{array}$ & $\begin{array}{c}\text { Percentage } \\
{[\%]}\end{array}$ \\
\hline Shandong & 74 & $9.97 \%$ & Fujian & 20 & $2.70 \%$ \\
Jiangsu & 58 & $7.82 \%$ & Heilongjiang & 19 & $2.56 \%$ \\
Liaoning & 49 & $6.60 \%$ & Yunnan & 19 & $2.56 \%$ \\
Zhejiang & 34 & $4.58 \%$ & Hubei & 17 & $2.29 \%$ \\
Sichuan & 32 & $4.31 \%$ & Tianjin & 17 & $2.29 \%$
\end{tabular}




$\begin{array}{cllccc}\text { Guizhou } & 30 & 4.04 \% & \text { Hunan } & 17 & 2.29 \% \\ \text { Anhui } & 29 & 3.91 \% & \text { Gansu } & 16 & 2.16 \% \\ \text { Hebei } & 27 & 3.64 \% & \text { Jiangxi } & 16 & 2.16 \% \\ \text { Guangdong } & 26 & 3.50 \% & \text { Shanghai } & 16 & 2.16 \% \\ \text { Henan } & 25 & 3.37 \% & \text { Jilin } & 15 & 2.02 \% \\ \text { Guangxi } & 25 & 3.37 \% & \text { Qinghai } & 14 & 1.89 \% \\ \text { Xinjiang } & 24 & 3.23 \% & \text { Shanxi } & 14 & 1.89 \% \\ \text { Shanxi } & 23 & 3.10 \% & \text { Henan } & 9 & 1.21 \% \\ \text { Chongqing } & 23 & 3.10 \% & \text { Ningxia } & 9 & 1.21 \% \\ \text { Inner } & 20 & 2.70 \% & \text { Tibet } & 5 & 0.67 \% \\ \text { Mongolia } & 20 & 2.70 \% & \text { Total } & 742 & 100 \% \\ \text { Beijing } & 20 & & \end{array}$

Leisure agriculture demonstration sites provincial distribution characteristics.the geographic concentration index.Using geographic concentration index analysis the concentration of leisure agriculture demonstration sites , the calculation formula is as follows:

$$
U=100 \times \sqrt{\sum_{i=1}^{n}\left(\frac{x_{i}}{M}\right)^{2}}
$$

$U$ the concentration index, $x_{i}$ the number of the leisure agriculture demonstration sites in $i$ province, $M$ the total number of leisure agriculture demonstration sites, $n$ The total number of provinces, $U$ Values between $0-100$, the bigger the $U$ value show that demonstration sites distribution more concentrat,the smaller the value of $U$ indicates that the sites distribution is more balanced. The total number of leisure agriculture demonstration sites $M$ is 742, $\mathrm{n}$ is 31 provinces. Using the formula to calculate the available $U$ is 21.62 , If leisure agriculture demonstration sites evenly distributed in 31 provinces, each province city should have 23.94 sites, calculated by the formula, the concentration index $U$ is 16.13 , less than 21.62 , The results showed that the distribution of leisure agriculture demonstration sites in all provinces is relatively concentrated.

Uneven index.Uneven index used to measure equilibrium degree of research object in different region ${ }^{[1]}$.Uneven index is available to analysis the equilibrium distribution of leisure agriculture demonstration sites in different provinces, using the Lorenz Curve to calculate, the formula is as follows:

$S$ : Uneven index, n: Province number, $w_{i}$ : The cumulative percentage . If $S=1$, the leisure agriculture demonstration sites are concentrated in the same province, If $S=0$ The leisure agriculture demonstration sites distribute evenly, If $S$ value between $0-1$, it means that the leisure agriculture demonstration sites distribute imbalance.

Gini coefficient.Gini mainly research discrete regional spatial elements distribution. The Gini coefficient is used to measure the space distribution of leisure agriculture demonstration sites, the calculation formula is as follows:

$$
\begin{aligned}
& G=1-\frac{1}{N}\left(2 \sum_{i=1}^{n-1} w_{i}+1\right) \\
& C=1-G
\end{aligned}
$$

$w_{i}$ the leisure agriculture demonstration sites quantity ratio accumulate from the first regions to the $i$ region. $n$ : the province number, $C$ : Distribution uniformity.The greater the Gini coefficient show that the higher the concentration degree and the lower the distribution uniformity ${ }^{[2]}$. According to the provincial leisure agriculture demonstration sites, $G=0.959, C=0.041$. Show that China's provincial leisure agriculture demonstration sites clustered and unbalance.

The tourist market geographical connection degree.Urban residents are the main source of leisure agriculture, leisure agriculture demonstration sites spatial distribution have obvious market orientation. Geography connection rate is index to reflect the contact degree of two economic factors in the geographic distribution.It is available to analyze the matching degree between the Leisure agriculture demonstration sites distribution and market distribution ${ }^{[3]}$. 
Geography connection rate calculation formula:

$V=100-\frac{1}{2} \sum_{i=1}^{n}\left|s_{i}-p_{i}\right|$

$V$ signify geographical contact rate, $n$ signify area number, $S_{i}$ signify leisure agriculture site in area $i$ accounts for the total number of nationwide, $P_{i}$ signify the urban population in area $i$ accounts for the nationwide urban population.Geographical contact rate value between $0-100$, the greater the value shows that economic factor cooperation degree is higher and spatial contact more closely.Base on the data of leisure agriculture sites and urban population in 2013,the value calculated to 99.79, it shows that leisure agriculture site and tourist market cooperation degree is high and urban aggregation is obvious,it also implies leisure agriculture mainly distributed in the eastern economically developed provinces and big city suburbs.

\section{Leisure agriculture resources development path analysis}

Leisure agriculture resources development path means choosing resources development type, layout pattern and investment patterns combine with development conditions such as regional natural, social, economic, ecological environment, potential customers.

Leisure agricultural resource development and operation type.The leisure agricultural garden.Agricultural sightseeing garden.Sightseeing park rely on resources such as crops, horticultural crops, fruit trees, flowers, tea, vegetables, provide the landscape and participation events to visitors,make the visitors enjoy the pleasure of experiencing farming work.Agriculture sightseeing garden can be subdivided into sightseeing orchard, sightseeing vegetable garden ,sightseeing flower garden, sightseeing tea garden, sightseeing melon garden,sightseeing bamboo garden, sightseeing chinese herbal medicine garden,ecological plantations, etc ${ }^{[4]}$.Such as Beijing Rich Brocade Earth,Beidaihe Jifa ecological agriculture sightseeing park, etc.Science and technology plantation. Relying on the advanced agricultural science and technology production mode,the plantation strengthen the technological, ecological, interest and artistry of production process to realize the combination of science popularization education function and leisure sightseeing function, operation scope include Agricultural Museum,High and new science and technology demonstration garden,Ecological agriculture expo garden,etc.Education plantations. The crop species planted in the plantation, morphological characteristics and shape characteristics, breeding biology and equipped facilities possess plentiful education connotation,such as special plants, tropical plants,hydroponic cultivation facilities, trees and vegetable Labels exhibition, traditional farming tools exhibition, etc ${ }^{[5]}$,then Provide visitors with outdoor teaching and experience site to understand agricultural production, agricultural science and technology knowledge .

Leisure Farm. Manufacturing leisure farm.Refers to rely on farming, forestry, animal husbandry, fishery and other large agricultural production base,developing leisure farm characterized by large-scale and intensive production.This kind of mode take production as the main function, and offers recreational activities such as visiting the agricultural intensive production process and participating in agricultural products processing production.Industry leisure farm.It's leisure agriculture projects based on forestry,grassland farming and fishery industry resources. The first one is the forestry leisure, develop management mode possess many recreational function such as artificial forest, natural forest, forest park; the second on is rural animal husbandry, developing agriculture projects such as sightseeing, animal husbandry and life experience, the grassland cultural immersion ; The third is recreational fishery, making full use of the oceans, islands, coastal zone and fishery production, fishery and fishing village cultural resources, carry out the activities as hunting fish, stream fishing shore fishing, boat fishing ,maritime competition,fishing operations,experience fishing village life,such as Shenzhen sea rural coastal tourist area.

Folk custom villages and towns. Using village resources such as ypical dwellings, features village, new village scenes, folk art as well as traditional architecture, temples, ancestral hall, etc in some economic, cultural and commercial history cities.develop leisure agriculture project base on local culture, folk customs, traditional theme,exhibition traditional culture and folk life in special villages and towns, let visitors experience the village folk, ecological art and new rural construction achievements,such as zhouzhuang, shanxi pingyao ancient city . 
Leisure agriculture resources development spatial layout.Scenic spot edge type.Relying on the visibility, reputation, influence and attraction,tourist market of famous scenic spot to development leisure agricultural industry.Scenic resources combination, industry complementary, customer sharing are developing trend.For example Anhui Xidi Hongcun in the Mount Huangshan industrial radiation circle, utilize Mount Huangshan scenic area advantage to development

Urban suburban.This kind of leisure agriculture layout in the major and medium city suburb or in the outer suburb areas, use these areas obvious geographical advantages, convenient transportation,communication conditions and relatively good natural and human environment to develop leisure agriculture projects.Large and medium-sized city social economic development and stability, huge source markets can effectively stimulate and promote the rapid expansion of leisure agriculture in suburbs, such as Suzhou future world forestry.

Characteristic rural area.This kind leiruse agriculture generally located in the characteristic folk culture and the characteristic agriculture rural areas, such as the characteristic vegetables, fruit production base, characteristic buildings etc.Urban residents are main tourist, based on the traditional agricultural resources, agricultural culture, folk resources,traditional culture and the characteristic village to carry out leisure activities,such as tourism,experience, education, work, shopping,etc.

Leisure agricultural resources development organization model.The government leading.This model is leading by the government to promote leisure agriculture industry development, through the formulation of relevant policies support and promote the construction ofleisure agriculture project ${ }^{[6]}$. This model includes the government constrction,government \&enterprises, and government\&company\&farmers three forms.Government\& company\&community \&farmer is the most common operation mode ${ }^{[7]}$.This model helps to mobilize the government, enterprises, farmers three party enthusiasm, driving the three power, and to play the advantages of each link of industry chain, vigorously develop the local leisure agricultural industry.It appears more targeted and operational especially in the economic development is relatively backward rural areas.

The enterprise leading.In the enterprise leading modle enterprises have full autonomy, the function of government is service and assistance.The private enterprises, joint-stock or other types of enterprises generally as the investment and operation entity to development, planning, operation and management.Through leasing land use rights from villages, and farmers to operate and manage the project. This model includes three forms as the enterprise independent investment, enterprise \& farmers, enterprise\&community \&farmer.

Individual operation.Individual operation refers to the local farmers or individual operators as the main investment entity to carry out leisure agriculture activities and gain economic benefits. This model is widespread because of small investment, low risk and earnings fast. But this kind mode is mostly farmers spontaneous operation, existing many problems such as small investment scale, similar operating projects ,unstandardized management, low level of industrialization, Inefficient social and ecological benefit, limited industry devolopment driven effect.

\section{References}

[1]Xie Zhihua,WuBihu.China resource-oriented tourism spatial structure research.Geographical Science,Vol. 28(2008),p.748-752.

[2]Wu Bihu.Tang Ziying. Tourist attractions spatial structure analysis- take China's first national 4A level tourist area as example.Human Geography,18(2003),p.1-5.

[3]Ma Yong,Shu Boyang.Regional tourism planning-Theory .Method.Case.Nankai University Press, Tianjin (1999), in press.

[4]Guo Huancheng.Zheng Jianxiong,edit.Leisure agriculture and rural tourism development on both sides of the Taiwan straits.China mining university press,Beijing (2004), in press.

[5]Chen Xiaoyan,Tian Fei.Ecological tourism agriculture development prospect.China Agricultural Information, Vol. 10(2008),p.11-12.

[6]Huang Wenxin.Cultivate the leisure industry to promote economic growth.Dialectics of Nature Studies, Vol. 10(2001),p.55-58.

[7]Wang Ruihua,Zhang Bing,Yin Hong.Foreign rural tourism development pattern.Yunnan Geographic Environment Research,Vol. 17(2005),p.73-76. 